\title{
Influence of Polyethylene Pipe on the Quality of Water in a Water Distribution System
}

\author{
Beata Kowalska ${ }^{1}$, Dariusz Kowalski ${ }^{1}$, Marian Kwietniewski ${ }^{2}$ \& Anna Musz ${ }^{1}$ \\ ${ }^{1}$ Faculty of Environmental Engineering, Lublin University of Technology, Lublin, Poland \\ ${ }^{2}$ Faculty of Environmental Engineering, Warsaw University of Technology, Warsaw, Poland \\ Correspondence: Beata Kowalska, Faculty of Environmental Engineering, Lublin Univ. of Technology, 40B \\ Nadbystrzycka Str., Lublin 20-618, Poland. E-mail: B.Kowalska@pollub.pl
}

Received: November 14, 2012 Accepted: January 3, 2013 Online Published: January 9, 2013

doi:10.5539/jsd.v6n2p1

URL: http://dx.doi.org/10.5539/jsd.v6n2p1

\begin{abstract}
In the past two decades economic considerations and very good mechanical parameters of polyethylene pipes contributed to more and more common use of the pipes for construction and repair of water distribution systems all over world. This paper presents the results of research into parameters of water collected from a polyethylene pipeline which was a part of an operational water supply network. We determined Total Organic Carbon (TOC) content and the content of organic compounds in the examined water samples using a multichannel gas chromatograph (Trace Ultra Thermo) coupled with a mass spectrometer (Polaris Q). We identified organic compounds bounded with antioxidants, added to polyethylene in the process of pipe production, in the water samples.
\end{abstract}

Keywords: water quality, distribution network, polyethylene pipes

\section{Introduction}

Polyethylene pipes, commonly used for construction of water supply networks and systems, are light, resistant to corrosion, and easy to assembly. Moreover, they offer an added value of high operational reliability. In Poland since 2008 polyethylene pipes have accounted for over $15 \%$ of the water supply networks, and their share in the water distribution systems have been growing continuously. IWA observed similar tendencies both all over Europe and internationally (Vreeburg \& Boxall, 2007; Seth et al., 2004).

Like most polymers, polyethylene is not resistant to the action of certain chemical and physical factors, for example UV radiation, temperature, mechanical load and oxidising agents. Therefore in the process of its synthesis and processing manufacturers add various additional components to it, and those components are to prevent the destruction and degradation of the plastic, and extend its service life (Hassinen, 2004). However, on the other hand, those substances contribute to creation of by-products, including aromatic compounds, e.g. phenols or quinones, which migrate into water, contributing to its deteriorated quality (Pospisil et al., 2002). Microorganisms use the organic compounds migrating from the pipes as a nutrient medium. The resultant growth of the microorganisms affects organoleptic characteristics of the water. The migration can take place in two manners: either directly through diffusion of chemical compounds into water, or indirectly, e.g. products of metabolism released by microorganisms developing on the surface of the pipes.

Research conducted by Skjevrak et al. (2003), Koch (2004) and Brocc et al. (2002) confirmed that PE pipes release around 100 various organic compounds into water. Denberg et al. (2007) classified the compounds as antioxidants, products of antioxidant degradation, products of metabolism released by microorganisms developing on the surface of the pipes, and derivatives of hydrocarbons with functional oxygen groups (e.g. esters, aldehydes) originating from damaged polyethylene chains. The most frequently detected ones are: 2,4-di-tert-butylphenol and 2,6-di-tert-butylbenzoquinone. These compounds are products of degradation of antioxidants with the following trade names: Irgafos 168, Irganox 1010, and Irganox 1076 (Skjevrak et al., 2003 ). Other detected compounds include carbon compounds, aliphatic hydrocarbons, alkylbenzenes, ketones, esters and BHT (4-methyl-2,6-di-tert-butylphenol) (Skjevrak et al., 2003; Lethola \& Miettinen, 2004). The scale of migration of organic compounds from the pipe material varies and depends, among other things, on the polymer structure, its temperature, vitrification and the chemical constitution of antioxidants (Pospíšil, 2007). 
Past research revealed that volatile organic compounds migrating from the pipe material result in deterioration of the organoleptic characteristics of water, first and foremost its taste and smell (Brocca, 2002; Skjevrak \& Lund, 2005; Rogers et al., 2005; Rigal \& Danjou, 1990). Products of antioxidant oxidation, such as aldehydes, ketones or quinines, can give a sweet or burnt oil aftertaste to water (Schweitzer et al., 2004; Tomboulian et al., 2004). 2,4-bis (dimethyl)phenol, benzene, benzothiazole, bis-(dimethyl)benzene, cyclohexanone, cyclopentanone, dimethylhexandiol, hydroxymethylethylphenol, isobutene, t-butanol alcohol, tetrahydrofurane, trichloroethylene are just some examples of compounds migrating from polyethylene pipes and influencing the taste and smell of water (Tomboulian et al., 2004). Heim and Dietrich (2007) and Schweitzer et al. (2004) analysed the problem of deteriorating taste and smell of chlorinated water, as well. Their research demonstrated that, apart from organoleptic changes in the water, the water which was in contact with polyethylene showed a decreased level of disinfectant after a test (Schweitzer et al., 2004). Chlorine disappearance might result from the reaction between chlorine compounds and antioxidants. Moreover, the pipe material can influence not only chlorine concentration levels but also contribute to formation of a biofilm in the pipes, having an indirect influence on the growth of microorganisms and decreasing the effectiveness of the disinfectant (Lethola \& Miettinen, 1971).

Polyethylene, like all materials used in the water supply business, is susceptible to the growth of microorganisms and formation of a biofilm on the inner surface of the pipes (Zacheus et al., 2000; Niquette et al., 2000). The factors influencing the intensity of the biofilm formation process include, i.a.: organic matter content in the water, type and properties of the pipe material, disinfection method employed, amount of the disinfectant used, hydraulic conditions in the water supply conduits. Proliferation of microorganisms results in deterioration of the biological properties of water, leads to creation of odour and colour, and accelerates the corrosion process inside the pipelines (Grabińska-Łoniewska, 2005; Lethola et al., 2006). Moreover, the presence of the biofilm on the inner surface of the pipes can contribute to the growth of heterotrophic bacteria and have a negative impact on the health of living organisms (Schewzyk et al., 2000; Lethola \& Miettinen, 2004). Research into the increase in the number of heterotrophic bacteria in the biofilm developing on the inner surface of PE pipes showed that the presence of ozonised water also contributes to an accelerated formation of the biofilm (Zacheus et al., 2000).

The objective of this paper is to analyse, on a preliminary basis, the quality of water which is in contact with a polyethylene conduit (HDPE) from an existing water supply network, in terms of the migration of organic compounds from the pipe material, and compare the obtained results with analyses, carried out in laboratory conditions, focusing on new HDPE pipes with material properties identical to those shown by pipes used in existing water supply networks. Further and more complex research will be possible once a section of a pipe is removed from the ground and subjected to structural testing in terms of pipe material as well as any sediment or biofilm. We have obtained permission from the water supply company to take a water pipe sample during the next routine repair.

\section{Method}

\subsection{Research Object}

The research focused on a fragment of an existing water supply network operated in a town of 50000 inhabitants. The fragment was a 3.5 kilometre long section of a conduit with external diameter of $160 \times 7.7 \mathrm{~mm}$, made fully of high density polyethylene (HDPE) and operated for the period of 5 years. The examined fragment of the network is situated on the outskirts of the town in a former industrial district (gelatine factory, which operated between 1970 and 1995, and included 3 small factory filling stations as well as a railway station), and it supplies water to a wastewater treatment plant and several industrial plants, and service companies. The plant was closed down before the HDPE pipeline was laid. The distance between the filling station and the pipeline oscillated between 95 and 250 meters. The railway station and factory car parks were paved with the drainage of rainwater to the sewage system within the last 10 years. A distribution network consisting of steel pipes $(25.7 \%)$, pipes made of grey cast iron (49.9\%), ductile cast iron (8.9\%), asbestos cement (3.9\%), PVC (2.7\%) and PE (9.0\%) feeds water to the examined fragment. The water comes from underground cretaceous intakes $55 \mathrm{~m}$ deep. It does not require conditioning or continuous disinfection, nevertheless it shows all applicable parameters as defined in Regulation issued by Minister of Health on 29 March (2007) and by Council Directive 98/83/EC (1998).

\subsection{Research Methodology}

The analysed section represents typical problems of network supply systems after the period of political transformation. After closing down of a neighbouring industrial plant the water flow rate is exceptionally low, ranging between 0.01 and $0.2 \mathrm{~m} / \mathrm{s}$, the top value was recorded for approx. 20 minutes per day. Both water flow rate values and their changes were determined based on a numerical hydraulic model comprising the whole 
network, which was created with Epanet software. The model has been verified and calibrated. The water age in the conduit in question, obtained from the simulation calculations, reaches a maximum of up to several days.

We conducted the research in the period of 12 to 17 August 2010, taking samples every day between 10:00 a.m. and 12:00 a.m. We selected underground hydrants situated at the beginning and at the end of the polyethylene pipeline as the sample collection points. We equipped the hydrants with standpipes and washed the hydrants each time. Samples marked with letter 'A' came from the beginning, and those marked with letter 'B' - from the end of the conduit. We poured the water samples into glass bottles, corked them tightly and transported immediately to Laboratory of Environmental Analyses at Faculty of Environmental Engineering of Lublin University of Technology, where the analysis of the samples took place. In the course of the research we determined key water quality indicators, namely $\mathrm{pH}$, total hardness, total alkalinity, as well as TOC (total organic carbon). We employed the potentiometric method (CPC-551 pH-meter made by Elmetron) to determine $\mathrm{pH}$ indicator; titration with EDTA disodium edetate solution to determine total hardness; and the colorimetric method against methyl orange to determine total alkalinity.

We determined total organic carbon (TOC) levels using SHIMADZU TOC-5050A automatic determinator which automatically collects a sample of an adequate volume for analysis.

We examined selected organic compounds using Trace Ultra Thermo multi-channel gas chromatograph coupled with Polaris Q mass spectrometer available at Faculty of Environmental Engineering of Lublin University of Technology. The working conditions of the apparatus were as follows: Trace Ultra (Thermo): feeder: PTV, fixed temperature mode, no flow splitting (splitless), temperature $320^{\circ} \mathrm{C}$, analytical tower: RTx 5 (Restek) $60 \mathrm{~m} \times 0.25$ $\mathrm{mm} \mathrm{df}=0.25 \mu \mathrm{m}$, furnace temperature programming: $75^{\circ} \mathrm{C}\left(2 \mathrm{~min}\right.$.), accretion $5^{\circ} / \mathrm{min}$. up to $300^{\circ} \mathrm{C}(5 \mathrm{~min}$.), carrier gas: He (99.9996\%) at a constant flow velocity of $40 \mathrm{~cm} / \mathrm{s}$; Polaris Q - Thermo: ion source temperature: $250^{\circ} \mathrm{C}$. Transfer line temperature: $275^{\circ} \mathrm{C}$. Monitoring of all ions within the range of 50.0 to $370.0 \mathrm{U}$ (Full Scan Monitoring). A 30 minute long HS-SPME (microextraction to stationary phase) followed. We moved the resulting isolated compounds to the feeder of the chromatograph and left them there for 10 minutes at the temperature of $270^{\circ} \mathrm{C}$ for desorption from fibre to occur. Identification of the organic compounds consisted in comparison of the obtained results with reference spectra available in the spectrum library NIST-2005 and Wiley 8th edition.

\subsection{Laboratory Tests Migration Test}

We compared the results of the field test with those obtained in laboratory conditions. We carried out laboratory tests in static conditions on the basis of a currently valid standard PN-EN 12873-1:2005 (2005), focusing on the migration (into water) of organic compounds contained predominantly in additional components added to the polymer in the process of its synthesis and processing. We prepared a pipe section around $50 \mathrm{~cm}$ long with external diameter of $160 \times 7.7 \mathrm{~mm}$ and split it in half along its axis. Prior to the test we rinsed the pipe with a jet of water from the water supply network (taken at a second stage pumping station operated within the considered network, named raw water) for $60 \mathrm{~min}$. Then we filled it with raw water (half the cylinder) and covered tightly with a self-adhesive thermoplastic foil (parafilm) designed to seal laboratory ware. The foil is very clean and it contains mainly linear hydrocarbons (paraffins) and a bit of olefins. In our analysis we skipped these compounds therefore they did not cause any interference in the testing process. We left the pipe in a dark room for the period of 3 days $(72 \mathrm{~h})$ at the ambient temperature of $20 \pm 2{ }^{\circ} \mathrm{C}$. After that period of time, we poured the water from the pipe to glass bottles and put it to further tests. We repeated the procedure three times. After each test, we marked the samples as N1, N2, N3. We carried out 2 chromatographic tests for each sample. The working conditions of the apparatus were identical to those created for the test of the water taken directly from PE pipeline operated within the network. We marked the water taken from the pumping station (feeding water into the network) as a raw sample.

\section{Results and Discussion}

Table 1 shows the sample collection schedule, key physical and chemical properties of the water, and the content of total organic carbon.

Changes in $\mathrm{pH}$ levels shown by the tested water were insignificant, varying from 7.40 to 7.56 . Total hardness varied from 6.78 to $7.50 \mathrm{mval} / \mathrm{dm}^{3}$, and total alkalinity levels fell within the range of 5.80 to $6.55 \mathrm{mval} / \mathrm{dm}^{3}$. Thus, none of the analysed water quality indicators changed significantly in the course of the entire measurement cycle. 
Table 1. Quality parameters of the water collected from a polyethylene pipeline which is a part of an operational water supply network

\begin{tabular}{lllllllll}
\hline Date & \multicolumn{2}{l}{$\begin{array}{l}\text { Total hardness, } \\
\mathrm{mval} / \mathrm{dm}^{3}\end{array}$} & \multicolumn{2}{l}{$\begin{array}{l}\text { Total alkalinity, } \\
\mathrm{mval} / \mathrm{dm}^{3}\end{array}$} & $\mathrm{pH}$ & \multicolumn{3}{l}{ TOC, ppm } \\
& $\mathrm{A}$ & $\mathrm{B}$ & $\mathrm{A}$ & $\mathrm{B}$ & $\mathrm{A}$ & $\mathrm{B}$ & $\mathrm{A}$ & $\mathrm{B}$ \\
\hline $12 / 07 / 2010$ & 7.35 & 7.03 & 6.10 & 6.00 & 7.54 & 7.52 & 3.38 & 4.13 \\
$13 / 07 / 2010$ & 7.08 & 7.03 & 6.05 & 6.10 & 7.52 & 7.49 & 3.50 & 4.15 \\
$14 / 07 / 2010$ & 7.15 & 7.13 & 6.05 & 6.20 & 7.56 & 7.46 & 3.57 & 3.73 \\
$15 / 07 / 2010$ & 7.10 & 6.93 & 6.05 & 6.20 & 7.40 & 7.39 & 3.98 & 4.04 \\
$16 / 07 / 2010$ & 7.23 & 6.78 & 6.05 & 6.15 & 7.45 & 7.49 & 3.51 & 4.42 \\
$17 / 07 / 2010$ & 7.33 & 7.15 & 6.45 & 6.55 & 7.46 & 7.43 & 3.79 & 4.46 \\
\hline
\end{tabular}

Concentrations of total organic carbon in the tested samples varied from 3.38 to $4.46 \mathrm{ppm}$. Thus, we observed a slight increase in TOC content caused, possibly, by the conduit material or the biofilm which, due to the fact that the pipeline had been in operation for several years, could have developed on the conduit surface. Table 2 below lists the organic compounds identified by means of the gas chromatograph.

Table 2. Organic compounds identified in water samples labelled A and B, collected from a polyethylene pipeline which is a part of an existing water supply network, ppb. RT stands for Retention Time, whereas CAS Chemical Abstract Service. Bold value is the average of A and B and \pm value is the Standard Deviation

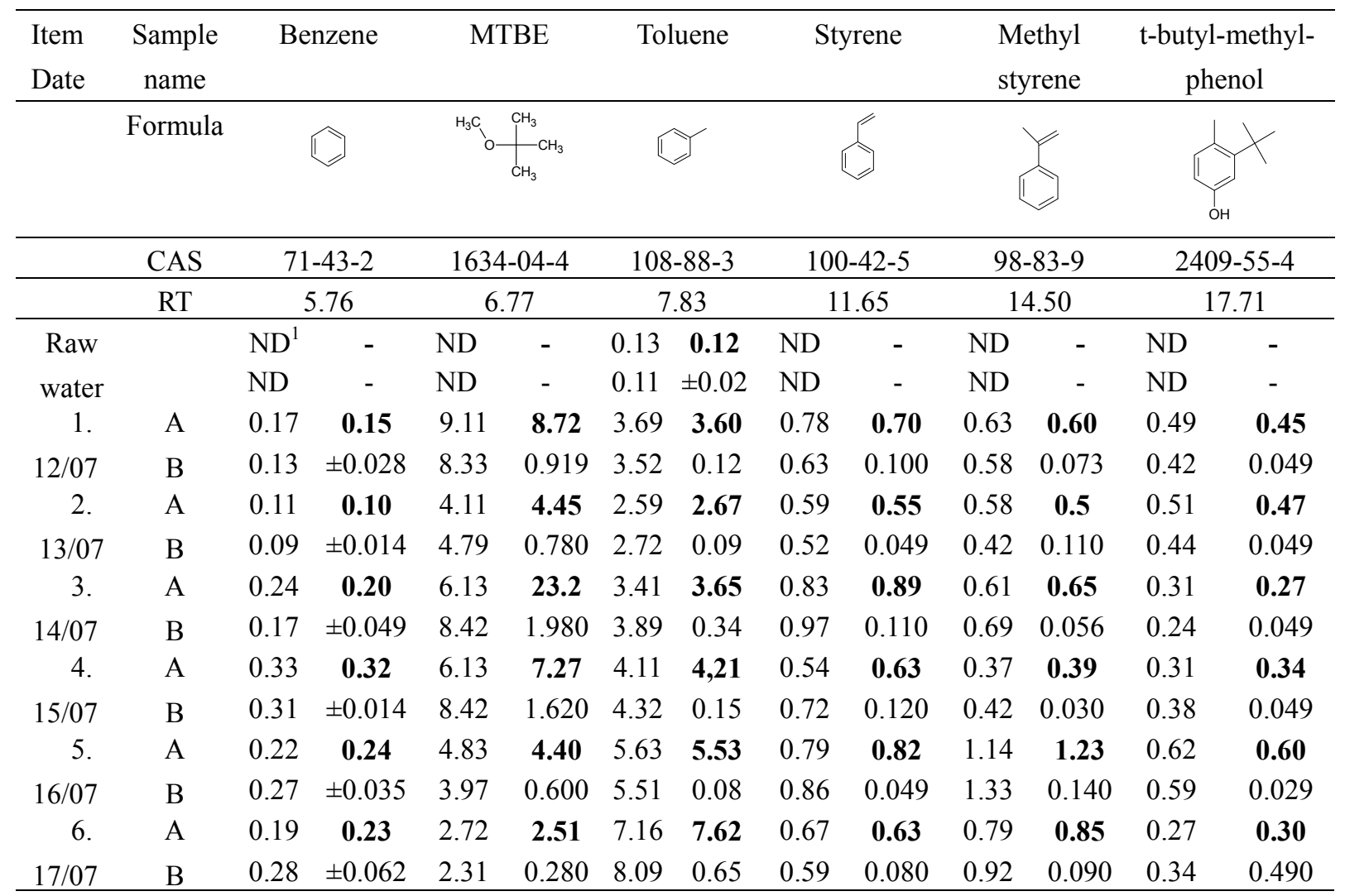

${ }^{1} \mathrm{ND}$ - not detected, MTBE - dimethyl-tert-butyl ether.

Our research identified the organic compounds bounded with antioxidants or products of their degradation, or polymer degradation. However the obtained concentration levels remained minute throughout the research cycle. The fact that water in the examined water supply network is not chlorinated might have contributed to those low 
levels obtained. Figure 1 below shows an example of a chromatogram for water samples taken from an operational polyethylene pipeline.

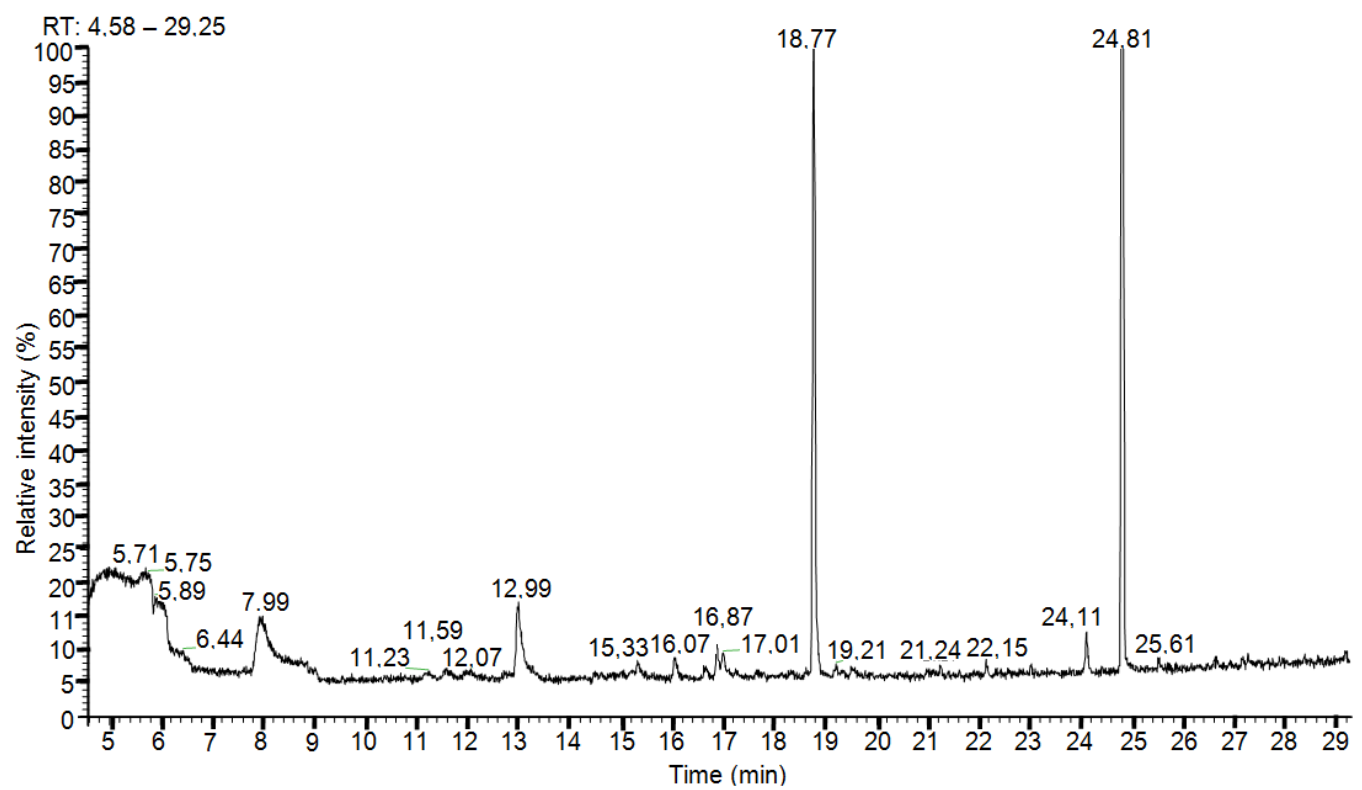

Figure 1. Example of a chromatogram of organic compounds determined in water samples collected from an operational polyethylene pipeline

A migration test carried out in laboratory conditions in accordance with standard PN-EN 12873-1:2005 (2005) (the test used a new polyethylene pipe with characteristics identical to those shown by a pipe in an operational water supply network) demonstrated the presence of organic compounds identical to those found in the course of the field research. The test revealed some differences in concentration levels of the compounds: in most cases the test detected higher levels in the water after the migration test. T-butyl-methylphenol was an exception because we did not detect its presence after the migration test at all. Table 3 below summarises the research results.

Figure 2 below shows an example of a chromatogram done after the migration test. We identified compounds bounded with antioxidants, and aromatic hydrocarbons such as toluene, benzene, styrene; and phenols such as t-butyl-methylphenol, i.e. degradation products of a commonly used BHT antioxidant (4-methyl-2,6-di-tert-butylphenol), in water examined both in field and laboratory conditions. In one case, we found toluene in raw water (feeding the water supply network, coming from the second-stage pumping station), however its concentration, amounting to $0.12 \mathrm{ppb}$, was much smaller than the one detected in water taken from the examined pipes: after the migration test toluene concentration varied from 6.66 to $8.97 \mathrm{ppb}$, whereas in the water samples taken from the operational pipeline the concentration varied from 2.67 to $7.62 \mathrm{ppb}$. We did not detect t-butylphenol after the migration test but in the water taken from the network its concentration levels varied from 0.27 to $0.60 \mathrm{ppb}$. This result points to degradation of BHT in a longer period of time. We recorded noticeably higher concentration levels, as compared with the concentrations found in the water from the network (from 2.51 to $23.2 \mathrm{ppb}$ ), after the migration test for benzene (from 1.82 to $4.23 \mathrm{ppb}$ ). But MTBE concentration is noticeably higher in the water from the network. We cannot exclude the possibility that this hydrocarbon penetrated from soil through the pipe wall into the water inside, contributing to the increasing concentration of MTBE. The fact that the pipeline runs underground in an post-industrial district supports that presumption. However, this conclusion should be confirmed by ground analysis, which has not been conducted. We found similar concentration levels of styrene and methylstyrene both after the migration test and in the tests of water taken from the network. 
Table 3. Organic compounds identified in water samples after a migration test carried out according to PN-EN 12837-1 (2005) standard, ppb. RT stands for Retention Time, whereas CAS - Chemical Abstract Service. Bold value is the average of A and B and \pm value is the Standard Deviation

\begin{tabular}{|c|c|c|c|c|c|c|c|c|c|c|c|c|}
\hline $\begin{array}{c}\text { Sample } \\
\text { name }\end{array}$ & \multicolumn{2}{|c|}{ Benzene } & \multicolumn{2}{|c|}{ MTBE } & \multicolumn{2}{|c|}{ Toluene } & \multicolumn{2}{|c|}{ Styrene } & \multicolumn{2}{|c|}{$\begin{array}{l}\text { Methyl } \\
\text { styrene }\end{array}$} & \multicolumn{2}{|c|}{$\begin{array}{l}\text { t-butyl-methy } \\
\text { 1-phenol }\end{array}$} \\
\hline Formula & & & \multicolumn{2}{|c|}{$\stackrel{\mathrm{H}_{3} \mathrm{C}}{-}-\mathrm{C}_{\mathrm{CH}}^{\mathrm{CH}_{3}} \mathrm{CH}_{3}$} & & & & & & \\
\hline CAS & \multicolumn{2}{|c|}{$71-43-2$} & \multicolumn{2}{|c|}{$1634-04-4$} & \multicolumn{2}{|c|}{$108-88-3$} & \multicolumn{2}{|c|}{$100-42-5$} & \multicolumn{2}{|c|}{$98-83-9$} & \multicolumn{2}{|c|}{$2409-55-4$} \\
\hline RT & \multicolumn{2}{|c|}{5.76} & \multicolumn{2}{|c|}{6.77} & \multicolumn{2}{|c|}{7.83} & \multicolumn{2}{|c|}{11.65} & \multicolumn{2}{|c|}{14.50} & \multicolumn{2}{|c|}{17.71} \\
\hline \multirow[t]{2}{*}{ N1 } & 3.17 & 3.25 & 1.13 & 1.17 & 8.61 & 8.97 & 0.89 & 0.90 & 0.35 & 0.39 & ND & - \\
\hline & 3.24 & \pm 0.49 & 1.22 & \pm 0.06 & 9.33 & \pm 0.50 & 0.92 & \pm 0.02 & 0.44 & 0.06 & ND & - \\
\hline \multirow[t]{2}{*}{$\mathrm{N} 2$} & 1.89 & 1.82 & 2.78 & 2.56 & 6.78 & 6.66 & 0.78 & 0.71 & 0.26 & 0.29 & ND & - \\
\hline & 1.76 & \pm 0.09 & 2.35 & \pm 0.30 & 6.54 & \pm 0.17 & 0.64 & \pm 0.09 & 0.32 & 0.04 & ND & - \\
\hline \multirow[t]{2}{*}{ N3 } & 4.11 & 4.23 & 1.14 & 1.39 & 8.23 & 8.07 & 1.01 & 0.95 & 0.54 & 0.45 & ND & - \\
\hline & 4.35 & \pm 0.17 & 1.64 & \pm 0.32 & 7.91 & \pm 0.22 & 0.89 & \pm 0.08 & 0.37 & 0.12 & ND & - \\
\hline
\end{tabular}

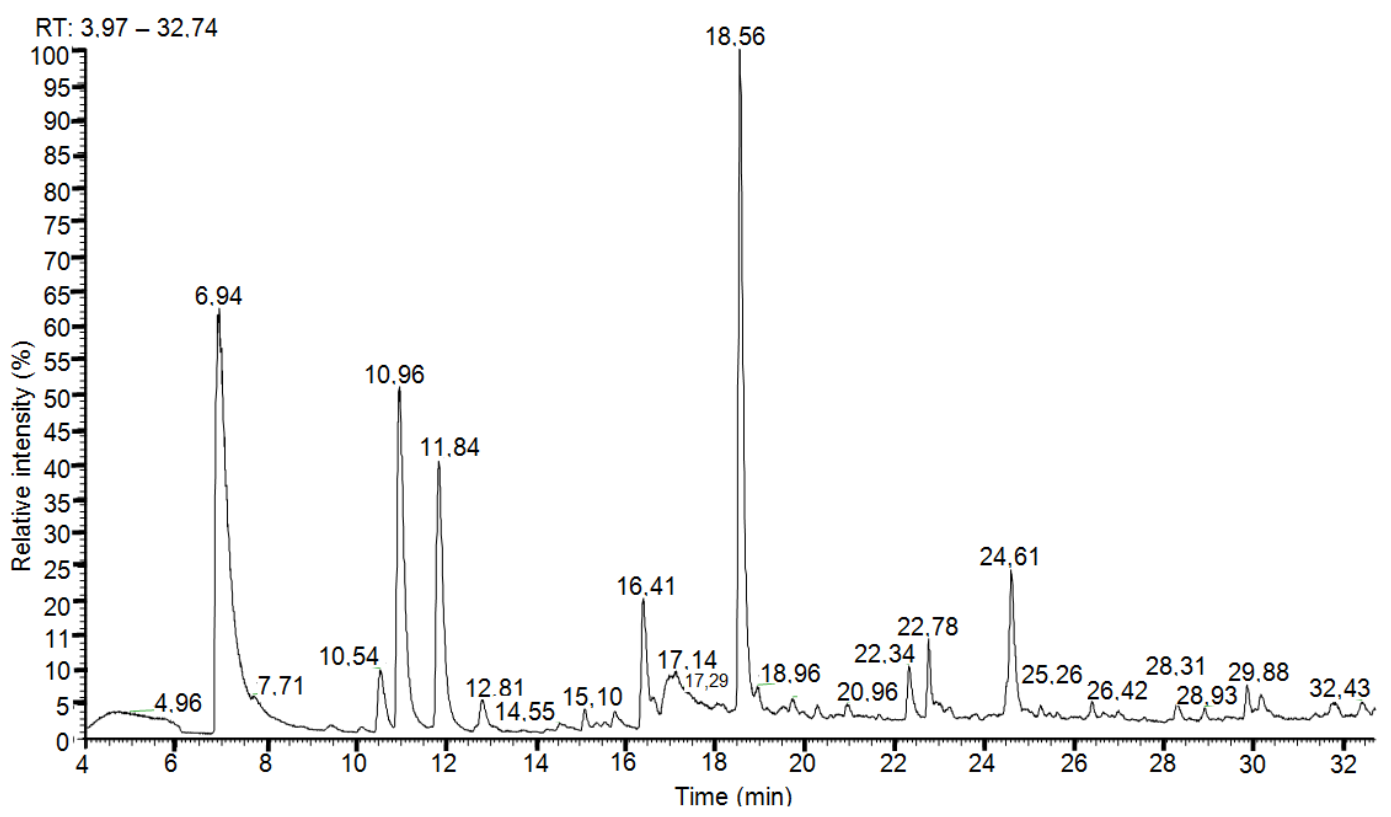

Figure 2. Example of a chromatogram of organic compounds determined in water samples from a migration test

\section{Conclusions}

The preliminary research leads to the following general conclusions:

The research identified compounds bounded with antioxidants (e.g. t-butyl-methylphenol) used in production of polyethylene, in the water flowing in a PE pipeline. This finding points to migration of organic compounds from the pipe material into the water which is in contact with the material. Recorded organic compound concentration values did not exceed the ppb norm (trace concentration), but still exist after five years of use. The concentration levels were higher only for benzene $(4.23 \mathrm{ppb})$. The observed compounds are not regulated by Polish law. The only compound mentioned by the Regulation on the Quality of Water to Be Used for Human Consumption issued by Polish Minister of Health on 29 March 2007, as amended on 20 April 2010 (Official Journal No 72, Item 466), benzene, must not exceed the concentration of $1 \mu \mathrm{g} / \mathrm{dm}^{3}$. 
Owing to the study, we noticed higher levels of MTBE (23.2 ppb) concentration in water from the field research as compared to laboratory tests $(2.56 \mathrm{ppb})$. Obtained test result discrepancies may indicate ground pollution in the pipeline area. However, this conclusion should be confirmed by ground analysis, which has not been conducted. Furthermore, tests of a greater number of new pipes are in order, as even pipes produced by one manufacturer may differ in composition. Consequently, it is difficult to draw unequivocal conclusions at this stage of the research. Nevertheless, the occurrence of that phenomenon allowed us to inform the water supply company and the Polish Engineers Association of potential deterioration of the quality of water flowing through PE pipes, particularly in contaminated post-industrial areas.

The fact that water in the examined network is not chlorinated could have influenced the values obtained in the research. Because related publications (Lundbäck, 2005) indicate that increased chlorine contents result in degradation of the inner parts of the pipes, decrease in the molar mass and formation of small axial cracks. Migration of compounds into water and reactions taking place on the surface of polyethylene result in rapid ageing of the material in the chlorinated water environment. Antioxidants degrade, they migrate into water and contribute to degradation of the polymer. Considering the aforementioned, similar tests should be conducted in networks where water is constantly subjected to chlorine disinfection.

The observed organic compounds related to antioxidants used for HDPE stabilisation may not only influence the quality of water, but also decrease strength properties of pipes after a longer period of time. In addition, the presence of organic compounds promotes the development of microorganisms and, as a result, of a biofilm on the inside pipe walls. Further research we intend to conduct on the analysed section of the water supply system will, therefore, revolve around these questions. Obtaining a pipe sample will be necessary for future research, however, it requires water supply company's consent. According to a promise made to the authors, it will take place during the next maintenance works in this area.

\section{Acknowledgements}

The authors wish to express their sincere gratitude to the Management Board of Waterworks in Pulawy City for help and kind cooperation.

This paper has been developed within the framework of implementation of the research grant No 4508/B/T02/2009.

\section{References}

Brocca, D., Arvin, E., \& Mosbæk, H. (2002). Identification of organic compounds migrating from polyethylene pipes into drinking water. Werearch, 36, 3675-3680. http://dx.doi.org/10.1016/S0043-1354(02)00084-2

Council Directive 98/83/EC of November 1998 on the quality of water intended for human consumption. Official Journal of the European Communities. L 330/32 5.12.98.

Denberg, M., Arvin, E., \& Hassager, O. (2007). Modelling of the release of organic compounds from polyethylene pipes to water. Journal of Water Supply: Research and Technology-AQUA, 56, 435-443. http://dx.doi.org/10.2166/aqua.2007.020

Grabińska-Łoniewska, A. (2005). Microbial contamination of drinking water distribution systems: problems and solutions. European Centre of Excellence CEMERA, Warsaw.

Hassinen, J., Lundbäck, M., Ifwarson, M., \& Gedde, U. W. (2004). Deterioration of polyethylene pipes exposed to chlorinated water. Polymer Degradation and Stability, 84, 261-267. http://dx.doi.org/10.1016/j.polymdegradstab.2003.10.019

Heim, T. H., \& Dietrich, A. M. (2007). Sensory aspects and water quality impacts of chlorinated and chloraminated drinking water in contact with HDPE and cPVC pipe. Water Research, 41, 757-764. http://dx.doi.org/10.1016/j.watres.2006.11.028

Koch, A. (2004). Gas Chromatographic Methods for Detecting the Release of Organic Compounds from Polymeric Materials in Contact with Drinking Water. Hygiene-Institut des Ruhrgebiets, Gelsenkirchen Germany.

Lethola, M. J., Laxander, M., Miettinen, I. T., Hirvonen, A., Vartiainen, T., \& Martikainen, P. J. (2006). The effects of changing water flow velocity on the formation of biofilms and water quality in pilot distribution system consisting of copper or polyethylene pipes. Water Research, 40, 2151-2160. http://dx.doi.org/10.1016/j.watres.2006.04.010 
Lethola, M., J., Miettinen, I. T., Lampola, T., Hironen, A., Vartiainen, T., \& Martikainen, P. J. (2005). Pipeline materials modify the effectiveness of disinfectants in drinking water distribution systems. Water Research, 39, 1962-1971. http://dx.doi.org/10.1016/j.watres.2005.03.009

Lethola M., J., Miettinen I. T., Keinanen, M. M., Kekki, T. K., Laine, O., Hirvonen, A., ... Martikainen, P. J. (2004). Microbiology, chemistry and biofilm development in a pilot drinking water distribution system with copper and plastic pipes. Water Research, 38, 3769-3779. http://dx.doi.org/10.1016/j.watres.2004.06.024

Lundbäck, M. (2005). Long-term performance of polyolefins in different environments including chlorinated water: Antioxidants consumption and migration, and polymer degradation. KTH Fibre and Polymer Technology, Stockholm.

Niquette, P., Servais, P., \& Savoir, R. (2000). Impacts of pipe materials on densities of fixed bacterial biomass in a drinking water distribution system. Water Research, 34(6), 1635-1640. http://dx.doi.org/10.1016/S0043-1354(99)00307-3

PN-EN 12873-1:2005 Influence of materials on water to be used for human consumption. Influence caused by migration. Part 1: Method employed to test factory manufactured products made of materials other than cement.

Pospíšil, J., Habicher, W.-D., Pila, J., Nešperek, S., Kuthan, J., Piringer, G.-O., \& Zweifel, H. (2002). Discoloration of polymers by phenolic antioxidants. Polymer Degradation and Stability, 77, 531-538. http://dx.doi.org/10.1016/S0141-3910(02)00112-X

Regulation on the Quality of Water to Be Used for Human Consumption issued by Polish Minister of Health on 29 March 2007, as amended on 20 April 2010 (Official Journal No 72, Item 466).

Rigal, S., \& Danjou, J. (1990). Tastes and odours in drinking water distribution systems related to the use of synthetic materials. Water Science and Technology, 40, 203-208. http://dx.doi.org/10.1016/S0273-1223(99)00558-2

Rogers, H. R., Norris, M. W., \& James, H. A. (2004). Effects of materials of construction on tastes and odours in drinking water. Reviews in Environmental Science \& Bio/Technology, 3, 23-32. $\mathrm{http}: / / \mathrm{dx}$. doi.org/10.1023/B:RESB.0000040010.64651.f9

Schewzyk, U., Schewzyk, R., Manz, W., \& Schleifer, K. H. (2000). Microbiological safety of drinking water. Annual Review of Microbiology, 54, 81-127.

Schweitzer, L., Tomboulian, P., Atasi, K., Chen, T., \& Khiari, D. (2004). Utility quick test for analyzing materials for drinking water distribution systems for effect on taste-and-odour. Water Science and Technology, 49, 75-80.

Seth, A., Bachmann, R., Boxall, J., Saul, A., \& Edyvean R. (2004). Characterisation of materials causing discolouration in potable water systems. Water Science and Technology, 49, 27-32.

Skjevrak, I., Due, A., Gjerstad, K. O., \& Herikstad, H. (2003). Volatile organic components migrating from plastic pipes (HDPE, PEX and PVC) into drinking water. Water Research, 37, 1912-1920. http://dx.doi.org/10.1016/S0043-1354(02)00576-6

Skjevrak, I., Lund, V., Ormerod, K., \& Herikstad, H. (2005). Volatile organic compounds in natural biofilm in polyethylene pipes supplied with lake water and treated water from the distribution network. Water Research, 39, 4133-4141. http://dx.doi.org/10.1016/j.watres.2005.07.033

Tomboulian, P., Schweitzer, L., Mullin, K., Wilson, J., \& Khiari, D. (2004). Materials used in drinking water distribution systems: contribution to taste-and-odour. Water Science and Technology, 49, 219-226.

Vreeburg, J. H. G., \& Boxall, J. B. (2007). Discolouration in potable water distribution systems: A review. Water Research, 41, 519-529. http://dx.doi.org/10.1016/j.watres.2006.09.028

Zacheus, O. M., Iivanainen, E. K., Nissinen, T. K., Lehtola, M. J., \& Martikainen, P. J. (2000). Bacterial biofilm formation on polyvinyl chloride, polyethylene and stainless steel exposed to ozonised water. Water Research, 34(1), 63-70. http://dx.doi.org/10.1016/S0043-1354(99)00113-X 